most of it in weapons research, first as British representative at Los Alamos and then as Director of Research at Aldermaston. His three years as chairman of the Atomic Energy Authority leave it well organized and successful. It is now likely to enter a period of contraction and change which will impose an even greater burden on the new chairman.

It is also known that Sir Harry Melville is retiring in September from his post as Chairman of the Science Research Council. He has been chairman of the council since it was established in April 1965, was previously Secretary of the Department of Scientific and Industrial Research, and has been professor of chemistry at both Aberdeen and Birmingham. He too will probably wish to return to academic life. The name of Professor B. H. Flowers has been frequently mentioned in speculation about his successor at the Science Research Council.

\section{Nuclear Information}

THE International Atomic Energy Agency is about to launch an ambitious scheme for collecting and processing technical information on atomic energy. At the end of December a working party drawn from sixtecn of the member countries of the agency accepted in principle what is described as the concept of "an international nuclear information system", and which has already been blessed with the acronym INIS. The International Agency has for some time been concerned to sponsor developments in the handling of information in nuclear physics, and has been carrying out some work within its own organization. No doubt the new organization will work closely with others such as the Neutron Cross Section Centre in Paris which is operated by the European Nuclear Energy Agency.

\section{Aid Distribution}

THE O.E.C.D. in Paris has now published statistics showing the way in which financial aid from advanced nations is distributed to developing countries. According to figures based on the membership of the Development Aid Committee of the O.E.C.D. (which includes Australia and Switzerland as well as the ordinary members of the organization), the total financial contribution to the less developed countries between 1960 and 1964 amounted to $\$ 42 \cdot 3$ billion. Of this total, governments contributed $\$ 25.9$ billion, or close on two-thirds. The contribution of multilateral agencies such as the various institutions of the United Nations amounted to $\$ 2.3$ billion, and the rest of the aid represented the investment of private companies in the economies of developing nations.

It appears that the members of O.E.C.D. have put Asia at the top of their list of recipient countries, for the flow of public money to Asian countries worked out at an average of $\$ 2,315$ million a year in the first five ycars of this decade. Africa comes next on the list with an average of $\$ 1,523$ million a year from government sources. In terms of the populations of the two regions, of course, Africa is the more generously treated in that its population of 280 million people is merely a third of that of the recipient nations in Asia. Aid to Latin America and to undeveloped countrics in Europe took $\$ 674$ and $\$ 438$ million a ycar respectively in the first five years of this decade. Except in Asia, aid giving appears to be more or less the same from one year to the next, although the present contribution to the economy of undeveloped countries on the American continents is much greater than it was in the fifties.

\section{Publishing in Physics}

THE Institute of Physics and the Physical Society, which has a long-standing interest in publishing of all kinds, is now planning to publish on its own account records of its own conferences and symposia. Three volumes, relating to conferences held in September, 1966 , have been or are about to be published at prices ranging from $£ 44 s$. to $£ 5$. Evidently the institute is hoping that it will be able to publish symposium proceedings more quickly and more cheaply than commercial publishers. Another of the benefits of the arrangement will be that librarians and others will be able to trace the publishers of particular conferences more easily than at present. Other learned societies will no doubt follow the experiment with interest.

\section{Less Smoking in Britain}

A SIGNIFTCANT decline in the consumption of tobacco in the United Kingdom is recorded in the fourth edition of the survey on the subject carried out each year by the Tobacco Research Council. Between 1964 and 1965, the total consumption of tobacco fell by four per cent to $255 \cdot 1$ million pounds. Since 1961 , when smoking was at its peak, there has been a decline of eight per cent, coupled with a substantial change in smoking habits in favour of cigars and against pipes and cigarettes.

The decline is more marked when expressed in terms of the consumption by individuals, and among adult male cigarette smokers consumption declined from an average of 4,010 cigarettes per head in 1961 to 3,580 per head in 1965. The rising trend of cigarette smoking among women since the mid-fifties has now apparently been halted, and has settled down at 1,860 cigarettes per head or roughly half as much as for men. The incidence of cigarette smoking among children between 10 and 15 years seems not to have changed significantly in the first half of the present decade, but the numbers of men smoking tobacco in all its forms have declined significantly between 1958 and 1965, particularly among the age groups above the mid-thirties. Thus the proportion of men between 35 and 49 not smoking tobacco at all increased by nearly a third between 1958 and 1965 , and amounted to 30 per cent at the end of the period. Although the proportions of women smokers are consistently lower than those of men in the same age groups, there has been no corresponding decline in the incidence of smoking in the years covered by the survey.

\section{Britain Five Years Ago}

Tur spate of primary publications of the 1961 census of the British Isles may soon be coming to an end, to judge from the appearance at the end of 1966 of the Summary Tables for Great Britain, together with the Household Composition Tables for England and Wales (H.M.S.O., $£ 1$ 19s, and $£ 3$ 7s. respectively). The 